Marquette University

e-Publications@Marquette

4-1-2006

\title{
The Turn in Economics: Neoclassical Dominance to Mainstream Pluralism?
}

John B. Davis

Marquette University,john.davis@marquette.edu

Published version. Journal of Institutional Economics, Vol. 2, No. 1 (April 2006): 1-20. DOI. (C) 2006 Cambridge University Press. Used with permission. 


\title{
The turn in economics: neoclassical dominance to mainstream pluralism? ${ }^{1}$
}

\author{
JOHN B. DAVIS \\ University of Amsterdam and Marquette University
}

\begin{abstract}
This paper investigates whether since the 1980s neoclassical economics has been in the process of being supplanted as the dominant research programme in economics by a collection of competing research approaches which share relatively little in common with each other or with neoclassical economics. A shortlist of the new approaches in recent economics includes game theory, experimental economics, behavioral economics, evolutionary economics, neuroeconomics, and non-linear complexity theory. Two hypotheses are advanced - one regarding the relation between economics instruction and economics research and one regarding the nature of the economics research frontier - to describe social-institutional practices that contribute to the replication of economics as a field. Two further hypotheses are advanced - one regarding the boundaries of the field and one regarding how the field appraises itself - to create a historical-methodological framework for evaluating the question of change in economics and change in recent economics in particular. Finally, the paper distinguishes three leading explanations - the 'breakdown' view, the 'takeover' view, and the 'maturity' view - of why neoclassical economics no longer dominates a mainstream economics.
\end{abstract}

\section{Introduction}

This paper investigates whether neoclassical economics may be in the process of being supplanted as the dominant research programme in recent economics by a collection of new, largely non-overlapping, competing research economics programmes that share relatively little in common either with each other or with neoclassical economics. I treat this new more diverse economics as a stage in the development of economics at the last century's end, provisionally label it 'recent economics', and date its beginnings to roughly around 1980. A shortlist of the new research programmes in economics that began to emerge more or less around this date would include game theory, experimental economics, evolutionary

1 I am grateful for comments on previous versions of this paper to Jack Amariglio, Mark Blaug, David Colander, Wade Hands, Matthias Klaes, Philip Mirowski, Jorma Sappinen, Esther-Mirjam Sent, Roy Weintraub, James Wible, and the reviewers of this journal. The usual disclaimer applies. 
economics, behavioral economics, neuroeconomics, and non-linear complexity economics. All involve significant departures from the neoclassical economics as generally understood (though there are elements of continuity as well), and all are especially associated with the ambiguity increasingly surrounding the meaning of the term 'mainstream economics'. Another way of putting the concerns of this paper is to ask, following David Colander (2000), whether not only is the term 'neoclassical economics' dead as a characterization of current mainstream economics, but whether it is dead as a characterization of how mainstream economics is currently evolving. Needless to say, any investigation of change that is on going must be speculative in nature. Four caveats of the current discussion consequently need to be stated at the outset.

First, the paper does not attempt to settle the issue of whether recent economics has in fact undergone such a change on the grounds that preliminary to doing so it seems necessary to address and clarify a number of interpretive issues central to explaining the process of change in economics and in recent economics in particular. It should be added that the question of change in any science or system of ideas is an extremely complicated one, and that historians and philosophers of science are hardly in agreement over what constitute criteria for identifying change. Thus it would be naïve - to say the least - to suppose that simple measures of change are readily available to decide this issue or like ones for other periods in the history of economics. The paper does, however, attempt to begin to make the case that there has been a turn in economics, and elaborates a number of hypotheses in support of this conclusion.

Second, the paper also does not operate from the perspective of any of the standard methodological frameworks regarding change in paradigms and research programmes, nor does the paper approach the issue of change from any particular rules-based perspective. Rather it attempts to state a set of resolvable claims about possible change in recent economics based on an assessment of its current social-institutional structure and relation to other disciplines. The paper thus relies on what may be termed an historical-methodological approach that uses historical analysis to generate methodological judgments, and then employs methodological thinking to carry out that historical analysis. In this respect it resembles to a degree the explicitly sociological analysis of Colander, Holt, and Rosser (2004), but it also differs from their analysis in its greater emphasis on a specific historical-methodological issue: namely, the boundaries of economics as a field and its relation to other fields.

Third, as noted, the paper does not treat change in economics as only involving a change in ideas, though that type of change is the ultimate focus. Rather the paper proceeds by examining economics as a set of social-institutional practices, and then, when referring to what has changed in economics, focuses on changes in what I broadly refer to as its 'content'. It is important to give greater attention to economics' social-institutional practices than I do here, but space constraints 
make the primary object of this paper a discussion of how thinking in recent economics has changed from how it has widely been perceived. ${ }^{2}$

Fourth, though it is reasonable to expect that a paper investigating issues of change in economics begin by defining 'neoclassical' and 'mainstream' economics, that task is not undertaken here on the assumption that a discussion of differences over what the former includes, as well as discussion of clear continuities between the former and the latter, do not affect broad differences between neoclassical economics and the recent new approaches. Colander (2000) makes a concise case to this effect; Mirowski (2002) makes a more extended historical argument for the same conclusion. However, it is also straightforward to note that attention to such things as strategic interaction (game theory), the psychological characteristics of human beings (behavioral economics), experimental practices, the arguments of evolutionary psychology, non-linear methods, etc., all constitute strategies of investigation that were largely absent in standard competitive marginalist thinking, which has been the mainstay of neoclassicism for many years.

Apart from these caveats, I should also emphasize the potential significance of the argument of this paper for readers of this journal. Evolutionary and institutional themes have been primarily associated with heterodox economics during the period of neoclassical dominance, but there is good reason to think they may be emerging as central themes in recent mainstream economics. For example, one important dimension of behavioral economics is that it reverses a century-long history in neoclassical economics in which the psychological characteristics of individuals were increasingly de-emphasized. However, the behavioral economics heuristics and biases program associated with the work of Daniel Kahneman and Amos Tversky re-introduces many of the same concepts, if in different form, long associated with the emphasis on habits in institutional economics. Relatedly, Vernon Smith, responding to experimental results regarding reciprocity, has asserted that a first principle of recent economics in his environment-institutions-behavior framework is that 'institutions matter' (Smith, 1989). Also, clearly the re-emergence of evolutionary economics recalls the Veblenian tradition. And arguably various versions of complexity economics, though sometimes highly formal, rely on many of the same basic themes found in evolutionary and institutional economics. I comment briefly on what these convergences may imply for economics in the future in the conclusion.

2 Important social-institutional practices for economics, in addition to those discussed in the next section, include the funding of research, the rise of laboratories, research assessment strategies, changes in advanced instruction, the 'Americanization' of economics, etc. See Mirowski and Sent (2001) for fuller treatment of the economics of science in general. 
The first section of the paper begins by discussing the nature of the process of change in recent economics, and advances two hypotheses - one regarding the relation between economics instruction and economics research and one regarding the economics research frontier - to describe social-institutional practices contributing to the replication of economics as a field. The second section outlines a historical-methodological framework for evaluating the question of change in economics, and then applies this framework to change in recent economics. Two further hypotheses - one regarding the boundaries of the field and one regarding how the field appraises itself - are advanced to explain the process of change in recent economics. The third section of the paper considers three leading explanations - the 'breakdown' view, the 'takeover' view, and the 'maturity' view - of why neoclassical economics no longer dominates a mainstream economics increasingly made up of a collection of different research programmes with neoclassicism playing a somewhat subordinate role. The fourth section concludes, and comments briefly on whether there might be future convergence around a new dominant approach in economics.

\section{Social-institutional practices and the process of change in economics}

On the surface the thesis that neoclassicism has lost or is losing its dominance within the field of economics is paradoxical, since neoclassicism remains solidly embedded in economics instruction, indeed arguably more so today than was the case even a short number of years ago. How can neoclassical economics no longer constitute the main approach in the field if it constitutes the main approach in economics instruction? This question raises the larger issue of the nature of the process of change in economics and the social-institutional practices that underlie it. Here I focus on this process of change in terms of the relationship between the two main practices that contribute to replication of the field over time, economics instruction and economics research, characterize the latter in terms of a research frontier, and advance two hypotheses about the nature of this process of change in recent economics.

\section{Economics instruction and economics research}

I take economics instruction and economics research to be the two main practices responsible for the replication of economics over time. How are they related? I hypothesize that over much of its history, but particularly in the period of postwar economics in which the field has become more highly professionalized, the direction of causation for change in economics has been from research to instruction, with content of instruction generally emerging with a lag as a summary or set of summaries of earlier research that has gained general 
acceptance. ${ }^{3}$ That is, changes in economics research generally precede, and ultimately generate changes in economics instruction, and not the reverse. This implies that during periods of change in the direction or content of economics as a whole, there are generally not only differences between economics instruction and economics research, but these differences may be greater the faster the rate of innovation in research. Of course, much that occurs in research is unsuccessful, while some successful research never gains a foothold in instruction, so the content of research at any one time does not predict well what future instruction will involve. The point rather is that when there are differences between the economics research and instruction - at least significant differences - a change in direction in economics research is likely to signal future change in economics instruction. ${ }^{4}$ Thus it is not paradoxical to say that neoclassicism is no longer dominant in economics as a whole, although it still constitutes the main course of instruction, if neoclassical economics no longer dominates economic research. Indeed, it is possible that, were non-neoclassical economics research particularly rapid and/or involved a number of significantly divergent new directions, there might even be a short-term increase in consensus over neoclassical instruction on account of the difficulties associated with establishing consensus over the value of new research, and then translating this new research into new instruction.

\section{The research frontier}

This view of economics research and instruction naturally raises the question as to what the main incubators for new economics research are. A model that seems appropriate to the postwar professionalization of economics as an academic discipline is a vintage or cohort model that focuses on waves of new doctoral degrees in the field on the grounds that on average new initiatives in research tend to be made at the outset of individuals' research careers, with generally modest changes in direction emerging over the balance of their research careers. That is, a vintage or cohort approach explains the change in research in terms of the idea of a moving research frontier (or set of frontiers). A change in the character of a research frontier would accordingly be said to occur when a significantly large number of qualitatively new doctoral initiatives occur in a relatively short period of time (cf. Colander, Holt, and Rosser, 2004). For example, if - as

3 This same argument is made in Colander, Holt, and Rosser (2004) and Colander (2005). Note that, while this thesis is obvious to many, there have been traditions in economics, for example at Cambridge in the first half of the last century, in which instruction played a more commanding role, and arguably had a significant influence on research. Contemporary science culture generally has research in the lead for reasons that have been investigated in recent economics of science.

4 As pointed out by one reviewer for this journal, as well as others at presentations of this paper, there are a number of anomalies associated with this transmission process, including contents that persist in instruction, despite changes in the content of research, uneven transmission across levels of instruction (advanced, intermediate, and introductory), appearance of instructional contents unrelated to changes in research, etc. 
seems to be the case - doctoral research using game theory is relatively rare before 1980, and constitutes a significant share of doctoral research after 1980, then one might then conclude that a new research frontier has emerged. A test of this sort of change in the economics research frontier would then involve surveying changing shares of different identifiable research orientations in new doctoral degrees over distinct time periods, particularly in leading doctoralgranting institutions, assuming, as seems reasonable, that these institutions tend to disproportionately influence change in research directions. ${ }^{5}$

A corollary of the research frontier hypothesis concerns the survival of older vintage ideas inside the research frontier. If research cohorts tend to maintain attachment to their original research initiatives, then a succession of research cohorts, which together fill out the overall research community, might be represented as an ordered array of waves of ideas and approaches, with the earliest waves at any one time being occupied by the oldest active researchers. This simplified model implies that attachment to earlier research initiatives generally decreases as the earlier waves lose active researchers to retirement. While earlier research approaches sustain a presence in the overall research community when there is significant change on the research frontier, barring new cohorts renewing these earlier initiatives, continued change on the research frontier implies that earlier approaches occupy a decreasing place in the overall research community over time. Yet until this process of change on the research frontier has gone on for some period of time, the bulk of research reflects what is behind the research frontier. Thus, not only is neoclassicism dominating economics instruction compatible with its being replaced by new approaches in economics, but its eventual replacement as a dominant approach is compatible with the bulk of economics research continuing to be neoclassical for some considerable period of time.

\section{A framework for investigating change in recent economics}

Here I outline an historical-methodological framework for investigating possible change in recent economics by characterizing the field, first, in terms of its boundaries with other fields, and, second, in terms of the field's reflexive, selfappraisal as carried out primarily in the sub-fields of economic methodology and history of economics.

\section{The boundaries and nature of economics}

Though I have spoken of economics as a field, it clearly should not be assumed that the nature and definition of economics as a field is fixed and unchanging,

5 Particularly important in this model is the role of the most prestigious doctoral programs. Thus on average their lead in new areas of research is followed by second tier programs, third tier programs follow second tier programs, etc. This also represents a broad simplification, and arguments can be made that innovation occurs below the top tier institutions. 
particularly when the content of the field itself is changing. For example, it is not clear that the traditional definition of economics in terms of the allocation of scarce resources fits very well with evolutionary or complexity economics. I thus try to simplify this issue by rather focusing on change at the boundaries of economics in terms of engagements with other disciplines, thus putting aside questions regarding the nature and definition of the field. More specifically, I focus on the expansion or contraction of the boundaries of economics in terms of the idea of export and import of conceptual contents across those boundaries to and from other disciplines. The boundaries of economics can then be said to expand with the export of its contents to other fields - a phenomenon popularly known as economics imperialism - while those boundaries can be said to contract with the import of contents from other fields - a phenomenon that has been associated with the idea of a 'reverse imperialism' (Frey and Benz, 2005).

Economics imperialism is often associated with the Chicago School, the Public Choice School, and more generally the application of neoclassical market concepts to non-market domains of social life, but it is also associated with the general adoption of rational choice analysis, market metaphors, and the quantitative methods of economics in a variety of non-economic fields of investigation (cf. Grossbard-Schechtman and Clague, 2002). How are we to explain cross-boundary transfers of science contents between fields? The 'imperialism' idea can be misleading, because it implies an unwelcome imposition, whereas the receiving field may be selectively appropriating nontraditional contents for reasons specific to its own development. In contrast, the export idea, as half of an export/import combination, is more neutral, and also points us toward a possible comparative assessment of fields in terms of their respective degrees of content homogeneity reflecting the degree of dominance of a field by one approach. That is, whereas fields with high levels of imported contents may be said to be comparatively heterogeneous or at least less homogeneous than fields with low levels of imported contents, so conversely fields with high levels of exported contents might be thought to be relatively homogeneous. On this view, economics imperialism as an export process can be said to be indicative of high levels of consensus among economists regarding preferred methods, concepts, and theories, and thus dominance of the field by a preferred approach. This is not to say that important internal differences in a field are absent in a period of imperialism, but only that, as a field with high levels of exported contents relative to other fields with high levels of imported contents, economics was relatively more homogeneous and dominated by neoclassicism at the height of its economics imperialism phase. ${ }^{6}$

6 This view of field homogeneity may be more characteristic of economics than other fields. Hausman's argument that economics is a relatively 'separate' science gives grounds for thinking that it is especially characteristic of economics (Hausman, 1992). 
Using the neoclassicism of the Chicago School and in particular Gary Becker's The Economic Approach to Human Behavior as emblematic of 1970s economics imperialism, ${ }^{7}$ this period might be regarded as the zenith of economics' relatively homogeneous organization under the neoclassical approach. But the 1970s was also the decade in which the neoclassicism's general equilibrium theory framework was beginning to be seriously questioned by many of its main proponents in what has come to be known as the Sonnenschein-Mantel-Debreu results (Kirman, 1989). Indeed, though there had been earlier criticisms of neoclassicism, the disenchantment with the general equilibrium framework in this instance was so severe as to lead a number of the theory's leading proponents to recommend that the neoclassical approach be abandoned altogether in favor of explaining economic behavior in game theoretic terms (e.g., Sonnenschein, 1985; also cf. Rizvi, 1994) - a recommendation which indeed was widely adopted in economics research and doctoral instruction beginning in the 1980s with the emergence of game theory as an increasingly key microeconomic method. Game theory, however, is made up of a set of contents that was imported into economics from mathematics (Mirowski, 2002). Thus the rise of game theory in economics appears to signal a point when economics imperialism was increasingly matched if not supplanted by a 'reverse imperialism', or a point when content imports rather than content exports increasingly defined the field. On the view here, then, economics became less homogeneous and therefore less dominated by neoclassicism as it made greater use of game theory, such that effectively the boundaries of what had been traditionally seen as economics contracted and shifted inward. This view is only reinforced by the fact that other new economics research programmes - experimentalism and behaviorism were also emerging at this time, and also depended heavily upon imported contents - experimentalism from many locations in science and behavioralism from psychology. Thus we might rather say that the overall shift in the field's contents in this period signaled an end to neoclassical dominance and the early emergence of a more pluralistic mainstream economics.

A changing balance of content exports and imports and boundary expansions and contractions, however, is hardly unique to recent economics, as the earlier example of an interwar pluralism followed by postwar neoclassicism attests (Morgan and Rutherford, 1998). We might accordingly take as an initial hypothesis for the framework advanced here that fields tend to go through recurring though non-regular cycles in which particular approaches are dominant in certain periods, followed by periods in which there is competition between different approaches. This cycle hypothesis of an alternating unity and plurality in the history of economics or any field, however, faces a serious challenge. How are we to distinguish between competition within a relatively unified

7 Note Becker's self-confident expression of the imperialism idea: 'the economic approach is a comprehensive one that is applicable to all human behavior' (Becker, 1976: 8). 
approach in a field and competition in a genuinely pluralistic environment involving significantly different approaches to that field? The answer to this question, and thus the grounds for saying that a cycle view has at least some plausibility, it seems, lies in whether we are able to advance a satisfactory criterion for saying when apparently different approaches are indeed genuinely different approaches. Here, I suggest, the content export/import logic may be especially helpful. When competing approaches import contents from distinct outside sources, they may be said to constitute genuinely different approaches in virtue of the different conceptual and theoretical foundations of different fields. That is, on the assumption that different fields are themselves distinct in virtue of having different conceptual and theoretical foundations, crossboundary content transfers juxtapose different foundations within single fields, thus setting up genuine competition between approaches. The 'cycle hypothesis', that is, ultimately depends on whether the 'different foundations' assumption can be reasonably said to apply.

By this criterion, moreover, the competing approaches in recent economics are indeed genuinely different approaches since they each originate from sources outside economics: game theory arose out of mathematics originally via John von Neumann and was subsequently developed in its classical phase by Robert Aumann and Reinhard Selten; experimental economics draws on a long history of experimental practice in natural and physical science almost entirely absent from economics; evolutionary economics reflects Darwinian biology (despite Classical/Malthusian economics and Schumpeterian antecedents); behavioral economics receives its impetus from recent psychology; and complexity economics arises out of computer and mathematical methods applied in many natural and social sciences well in advance of their recent appearance in economics. Were we consequently to demonstrate that these approaches jointly occupy a significant share of the recent economics research frontier, say, in terms of successive recent doctoral cohorts, a process of replacing neoclassical dominance in economics by a more pluralistic mainstream economics could be said to be in motion with different research approaches and their different foundational commitments competing with one another within the field. ${ }^{8}$

But this conclusion might still be challenged were it to be argued that there is selection bias in the import/appropriation process by which recent economics has drawn content from other fields. Were imports only to occur which were broadly consistent with the neoclassical approach, an argument could be made that the new environment is less pluralistic than the distinct sources of these imports seem to suggest. ${ }^{9}$ Indeed one reason to think that current mainstream economics is

8 One commentator on this paper suggested that changing in-field and out-of-field citation practices might provide a basis on which the influence of other disciplines on economics could be assessed. But influence transmitted in ideas is not reliably captured by citation patterns for a variety of reasons.

9 This issue is particular relevant to behavioral economics in that a number of leading researchers have argued behavioral economics is not inconsistent with neoclassical economics (e.g., Camerer and 
not especially pluralistic is the continuing divide between mainstream economics and heterodox economics. From this vantage point, it could be argued that change within the mainstream has involved a selective appropriation process that systematically excludes certain types of heterodox contents (Davis, 2006). However, if for the moment we leave this divide in place, and consider the development of mainstream economics by itself, it can also be argued that selection bias has not been a significant factor within the development of the mainstream. A case to this effect has been made by Colander, alluded to at the outset, who identifies a set of six principles he sees as central to neoclassicism, and argues to be absent from new approaches in recent economics (Colander, 2000).

Thus at one and the same time selection bias both appears to exist (with respect to heterodox economics approaches) and be absent (in Colander's argument). How are we, then, to address its weight and significance? We might begin by noting that, even were selection bias to exist in important degree, it would still be an open question as to the extent to which it could be said to domesticate different types of content imports. Thus what is needed is some way of assessing the balance arrived at in recent economics between accommodating selection and truly outside content, in order to determine whether or not selection bias has been sufficient to overcome the pluralist impulses in recent economics. I suggest a simple 'intelligibility test' for this purpose, and demonstrate this test by example as follows. Whereas for neoclassicism in the 1970s individuals trained in different sub-fields in economics (labor, trade, etc.) were generally able to understand one another's research on account of shared marginalist principles and methods, in recent economics it appears increasingly rare for individuals trained in different research approaches (e.g., game theory versus non-linear complexity theory) to understand one another's research. If this is so, then we might say that in recent mainstream economics, though selection bias is no doubt present in some degree, it does not seem sufficient to overcome the pluralist tendencies in the field at the current time.

This may of course change in the future were different research approaches in recent economics to begin to converge. On the argument here, this could occur were different approaches to converge on specific foundational issues imported along with content from their respective origin fields. For example, though originally game theorists and experimental economists were largely at odds over the role of deduction and experiment in economics, these differences appear to be narrowing, as economists are now increasingly engaged in experimentally testing game theory predictions (e.g., Camerer, 2003). A 'cycle hypothesis' of an alternating unity and plurality in the history of economics or any field, then, would include both divergence and convergence stages, where the former creates

Loewenstein, 2003), while, at the same time, other researchers have argued the opposite (e.g., Cubitt, Starmer, and Sugden, 2001). 
conditions in which a new dominant approach may possibly emerge, and involves an increasing effort to reduce differences over foundational content, perhaps also accompanied by a period of a reduced rate of borrowing from outside fields. But again, it is important to emphasize that this is only an hypothesis subject to further investigation.

\section{Economics' self-appraisal in economic methodology and history of economics}

There are a variety of ways in which fields and the individuals in them reflexively engage in a process of self-appraisal. The sub-fields of economic methodology and the history of economics themselves constitute reflexive practices in economics in that their object of investigation is economics as a field, whereas the object of investigation of economics itself is economic life, or in the case of the other sub-fields of economics some domain of economic life. That economic methodology and the history of economics are particularly important among reflexive practices in economics is evident from their institutionalized recognition as sub-fields and their accordingly systematic character. ${ }^{10}$ What I discuss here, then, is how cyclical shifts in the boundaries of economics over time may be thought to affect the relationship of the field of economics as a whole to these two sub-fields or at least the reflexive practices they involve. In connection with the change in recent economics in particular, I attempt to say how these sub-fields may change in status and in their relation to economics as a whole, should it be that economics is moving from neoclassical dominance to mainstream pluralism. First, then, what is the status of these fields in the period in which neoclassical economics has been dominant?

By most accounts, the status of economic methodology and the history of economics as sub-fields in economics over the last several decades is believed to be a declining one (Weintraub, 2002). Though by some measures the two subfields have prospered as independently professionalized sub-fields (Davis, 2002, 2003), interest in and attention to them on the part of practitioners generally and in the field as a whole appears to have steadily declined. Indeed, over the last two decades most economics doctoral programs have eliminated instruction in the history and methodology of economics. Further evidence of the declining status of history of economics might be established by evaluating citation patterns to determine the extent to which research in the sub-fields is decreasingly cited outside of the two sub-fields, as compared with the experience of other sub-fields. Another relevant measure would be the extent to which economic methodology and history of economics research has become increasingly concentrated among individuals for whom it is their primary subject of research. But assuming there

10 Of course practitioners also evaluate their field in a reflexive manner since they judge how results of research reflect research questions current in the field. While this focus brings certain advantages associated with close contact with research problems, it also tends to bracket out larger reflexive issues associated with the nature and status of the field over time. 
has been a decline in status of the two sub-fields, how might this development be explained in terms neoclassical dominance of economics?

Taking economic methodology and the history of economics to be the primary reflexive practices in economics implies that the decline in the status of these fields is tantamount to a decline in the field's involvement in self-examination and selfappraisal. A reasonable hypothesis explaining why a period of dominance by one approach might produce such an outcome is that in periods dominated by particular approaches a lower value is placed on self-examination and selfappraisal on account of the absence of competition from other approaches. The rationale is straightforward: because the field is largely perceived to be identical to the dominant approach to it, the issue of there even being a relation between it as an approach and the field as a whole does not easily arise. A test of this thesis would be whether a survey of neoclassical economists produced a consensus view that neoclassical economics is essentially identical with economics per se. In contrast, in periods when there are competing approaches to the field, proponents of these different approaches could be expected to place a higher value on economic methodology and the history of economics, because, unlike what occurs when one approach is dominant, positioning one's approach relative to another depends upon stating one's relation to the field as a whole in a relatively convincing manner. This can be understood to be primarily a matter of the strategy appropriate in a more competitive environment, but it can also be understood to be a matter of how practitioners from different research approaches with origins in other fields attempt to sort out conflict over foundational issues. A possible test in this regard would be to determine whether self-identified, mainstream economists are active in justifying the value of their research approaches in terms external to those approaches, such as might be addressed in terms of arguments from the methodology and history of economics.

All of this does not imply, however, that economic methodology and the history of economics as professionalized sub-fields per se need necessarily gain in status in a period of a more pluralistic economics. In an environment of competing research programmes, methodology and history arguments might well arise indigenously, as it were, among practitioners who are willing to make use of such arguments, but might not be prepared or interested in engaging the relevant professional literatures in depth. One example in this regard is the experimentalist, Vernon Smith, who, in contesting the deeply entrenched deductivist tradition in economics in an effort to justify empirical methods in economics research, has made explicit use of the Duhem-Quine methodology principle, though without paying heed to the extensive methodology literature on the subject (Smith, 1994). Another example is Richard Thaler, who contributed a series of articles to the Journal of Economic Perspectives meant to make a case for insights from behavioral economics, and used Thomas Kuhn's concept of anomalies as a general title for the series, but ignored the extensive discussion 
of the concept of anomalies in the methodology literature (e.g., Thaler, 1987). Indeed, if practitioners are reluctant to make use of the history and methodology professional literatures, but still wish to use arguments of this character, they might simply do so in a more implicit manner by adopting and modifying methodology and history arguments they perceive to be 'in the air' according to their more immediate needs.

A further source of a non-standard methodology and history argumentation that might emerge in new research programmes would involve researchers making use of forms of methodological argument specific to the origin fields from which these new approaches are drawn. Because the content imported from these fields likely carries with it underlying foundational concerns in the field from which it is drawn, it is reasonable to expect that economics researchers who import this content will advance methodological arguments based on these foundations, particularly where these are in conflict with standard foundational concerns in economics. For example, the idea of path-dependency, which underlies reasoning in recent complexity and evolutionary economics, has origins in history via Paul David and in mathematics via Brian Arthur, but, because the idea of path-dependency does not sit easily with equilibrium theorizing, both have made special efforts to explain the concept in terms of its use in its origin fields (e.g., David, 1985, 1994; Arthur, 1982, 1994). Thus, non-standard methodology and history argumentation might materialize in new forms when fields import outside contents. Wade Hands (2001), in fact, has argued that the sub-field of economic methodology has moved toward an implicit recognition of this type of development in recent years, in the process accommodating an infusion of new ideas about methodological thinking appropriate to economics. Abandoning an earlier strategy of drawing concepts and principles 'off the shelf' of standard scientific philosophy, methodologists have come increasingly to rely on contemporary science theory to explain economic reasoning. Contemporary science theory, however, 'naturalizes' on a variety of different science programmes, so that the effect is to incorporate different foundational themes in recent methodological thinking in a variety of different ways. How does one go about investigating and documenting this sort of borrowing process? One way would be to evaluate keyword patterns to track concepts irrespective of their origins, as has been successfully done by Matthias Klaes in connection with the concept of transaction cost (Klaes, 2000).

\section{Explanations for the change in recent economics}

Here I distinguish three leading explanations regarding why neoclassical economics may be said to have ceased to be the dominant research programme in contemporary economics: (i) the 'breakdown' view, (ii) the 'outside takeover' view, and (iii) the 'maturity' view. The three explanations are presented separately simply to distinguish them clearly as different strands in recent 
thinking about the change in economics. But proponents of the general view, that neoclassicism has ceased to be dominant, often draw upon elements of more than one explanation, either supposing they work simultaneously or seeing them as working in succession. The three explanations should all be viewed in the context of historical influences operating on economics, such as war, depression, changes in technology, and globalization. These sorts of influences are discussed very little here as explanations for change in recent economics for two reasons. First, as typically sustained historical forces, they are generally subtler and less clear in manifesting their effects on change in economics - a relatively rare exception being the clear connection between the reception of J. M. Keynes's work and the Great Depression. Second, allowing that historical forces do influence change in thinking in economics, explanations of such change are nonetheless cast primarily in terms of changes in the content of the field. Thus, while the Great Depression was an important stimulus to Keynesian macroeconomics, Keynes argued for his views in terms of what was wrong with the thinking of his predecessors (Say's Law type thinking) and in terms of what was right about his (equilibrium unemployment, effective demand, the role of money, etc.).

\section{The 'breakdown' view}

The 'breakdown' view is that, with the postwar development of axiomatic general equilibrium theory, neoclassical economics became a highly unified albeit also flawed conceptual structure possessing inherent barriers to its own further development that have become increasingly manifest in a number of important 'impossibility' results. Kenneth Arrow's impossibility theorem is both the first example and the principal source of the idea of neoclassicism as a highly unified conceptual structure that is the source of its own limitations, in this instance, in terms of its inability to explain social choice (Arrow, 1963 [1951]). Amartya Sen's impossibility of a Paretian liberal theorem subsequently showed that neoclassicism was inconsistent with the idea of individual liberty (Sen, 1970). The 1960s Cambridge capital controversies then raised the specter that neoclassicism was internally contradictory with respect to its scarcity rationale in connection with the concept of aggregate capital (cf. Cohen and Harcourt, 2003). Finally, The 1970s Sonnenschein-Mantel-Debreu results - that the arbitrariness of aggregate excess demands in general equilibrium models ruled out almost all standard comparative static reasoning in economics - went yet further in saying that general equilibrium theory was essentially empty of meaningful claims - an 'Emperor's clothes' thesis, as it was put by Alan Kirman, once a strong proponent of general equilibrium theory (Kirman, 1989; Rizvi, 1994). ${ }^{11}$

11 ' $\mathrm{I}] \mathrm{f}$ one maintains the fundamentally individualistic approach to constructing economic models, no amount of attention to the walls will prevent the citadel from being empty. Empty in the sense that one cannot expect it to house the elements of a scientific theory, one capable of producing empirically falsifiable propositions' (Kirman, 1989: 126). 
The 'breakdown' view involves the most radical appraisal of neoclassicism, though it does allow for its continued development, if only in the form of minor refinements that cordon off the theory's more fundamental problems. The implication, however, is that this sort of development is too modest to sustain the interest of researchers, and/or the sense that the theory is deeply flawed will ultimately lead researchers, especially younger ones, on to new theoretical approaches. Left unresolved by most of those who see neoclassicism as breaking down is whether one should expect the theory to be replaced by an alternative, still relatively unified conceptual structure that is not flawed, or whether the idea of a unified conceptual structure is itself flawed, and that economics might therefore be expected to exhibit a more pluralistic landscape in the future. Additionally, the former view, which is arguably the majority view, might come about as a result of either one stronger approach within the array of new research programmes emerging vis-à-vis all others or through convergence of several different approaches on shared assumptions.

\section{The 'outside takeover' view}

One of the characteristics of neoclassicism at its height was the export of its concepts and methods of reasoning to non-economic fields. But economics also has a long history of importing content from other fields (Mirowski, 1989, 2002; Sent, 1998). There seem to be at least two models for how this might occur. I have suggested that importing content from other fields is likely to occur when no one approach is dominant in a field, on the grounds that the absence of a dominant approach means there is no a clear view in the field as to what type of content appropriately describes the field. On this view, new approaches with outside origins compete until one is successful in representing the field. At that point, the field's self-conception is re-determined in terms of this successful approach. But it might alternatively be argued that such imports occur even when fields have dominant approaches, on the grounds that fields thus organized have special advantages in integrating non-field content in virtue of their being relatively well-developed structures. Philip Mirowski makes this argument with respect to the nineteenth-century emergence of neoclassicism via appropriation of physics thinking (Mirowski, 1989). Over time, then, an accumulation of such appropriations could have transformative effects on the dominant approach

and the field. One might, for example, also consider the steady adoption of mathematical methods in economics as having this sort of effect, and then argue that a dominant neoclassicism gradually evolved into contemporary formalist, mainstream economics by way of this kind of process, as does Mark Blaug with respect to the rise of postwar neoclassical formalism (cf. Blaug, 2003).

Whether one employs one model or the two in combination, however, the general view here is that all fields are in a state of continual transformation, sometimes in a gradually and almost imperceptible manner or sometimes more dramatically and convulsively. Essentially fields possess an at best transitory 
stability in terms of their content and scope, and the very concept of a field is at bottom artificial and arbitrary. From this perspective, the idea of a field having cycles of dominance and pluralism is also suspect or short-term in focus, since this would assume some long-term stability in the idea of a field. Taken to its extreme or in the long-term, fields might even disappear altogether over time as entirely different organizations of their contents, together with the addition of contents not traditionally associated with those fields, come about.

\section{The 'maturity' view}

This view might be thought a variant of the 'breakdown' view minus that view's claims about the problematic character of neoclassicism. The essential idea here is that, since any given approach involves a relatively set conceptual apparatus, any approach can explain only so many phenomena. Then, once an approach has been fully developed and applied to all the phenomena it might explain, it is 'mature' in the sense of having completed its full range of possible tasks. Any given approach thus undergoes a development process that must ultimately come to a natural conclusion, after which researchers turn to new approaches. David Colander has argued this has been the case with neoclassicism (Colander, 2000, 2001). Emphasizing the role of the research frontier, he sees mature research programmes as offering declining opportunities to new researchers, and suggests that doctoral supervisors, who have a clear view of what remains to be done in a given research programme, attract and direct new researchers toward issues that fall either on or outside the boundaries of the programme (Colander, 2001). He reinforces this argument with an emphasis on the changing role of technology. Computing technology has clearly advanced significantly in recent decades, and this has both allowed previously intractable problems within the neoclassical research programme to be addressed and eliminated as outstanding issues, and has also created new horizons for economics that go beyond the neoclassical programme.

Neoclassicism, then, is not so much a failed programme as a finished one. This is not to imply that a finished programme is without its limitations. Rather the general idea is that the programme works reasonably well within its defined scope, and, where it does face limitations, these do not threaten the integrity of the programme per se. That is, the motive for abandoning a programme at the field's research frontier is not any fundamental disenchantment with it, but rather awareness that more rapid development of economics is available in newer programmes in earlier stages of development. Strictly speaking, then, the neoclassical programme will never be abandoned altogether, even were research to be concentrated increasingly on other research approaches. Since, within its scope, neoclassicism is regarded as reasonably successful, applied research that does not seek to extend the basic framework can continue indefinitely with ever-new applications. This is arguably reflected in the wide use of standard microeconomic models in a variety of policy contexts. Thus, unlike the other 
two views, the 'maturity' view allows for a sustainable if no longer dominant neoclassicism; though, of course, it is also conceivable that even a relatively secure but no longer dominant view could later be seen as offering diminishing returns.

\section{Conclusion}

This paper investigates whether neoclassical economics might be in the process of being replaced by a collection of new competing research programmes, and thus whether neoclassical dominance is being replaced by a new mainstream pluralism. In an effort to produce an historical-methodological examination of the issue, the paper emphasized the importance of economics instruction and economics research as two key practices central to the replication of economics as a field, and hypothesized, first, that the direction of causation for change in economics is from research to instruction, and, second, that research changes on a continually moving research frontier. These two hypotheses enable us to say that the non-neoclassical development at the economics research frontier provides evidence that neoclassical dominance of economics is being supplanted by a new mainstream pluralism.

The more systematic, historical-methodological part of the paper involves an export/import model across field boundaries, combined with a characterization of economics' self-appraisal process in terms of economic methodology and history of economics. The export/import model is used to propose a (non-regular) cycle hypothesis of alternating unity and plurality in the history of economics. On this hypothesis, neoclassical dominance has likely been supplanted by a mainstream pluralism, because the new research programmes in economics all have imported content from outside fields with different, non-economic foundations so as to produce a juxtaposition of differently based approaches within economics. In regard to the self-appraisal process in economics, the paper hypothesized that methodology and history of economics are in retreat in periods when the field is dominated by one approach, but regain importance, if not always in the traditional form, in periods of pluralism. On this hypothesis as well, neoclassical dominance has likely been supplanted by a mainstream pluralism, because, in contrast to neoclassical economists, contributors to the new research programmes in economics have shown an interest in making use of methodology and history arguments to justify their departures from neoclassicism, and differentiate their approaches from each other. The paper concludes with brief review of three leading explanations of why neoclassicism seems to have been supplanted by a new mainstream pluralism.

In closing, I comment briefly on whether a new mainstream pluralism might ultimately converge upon a single, new dominant research programme that draws from the existing new research programmes in economics and perhaps neoclassicism. As noted above, there is already a new wave of doctoral 
research that combines game theory, experiment, and behavioral assumptions. On the analysis here, then, convergence could come about were the different foundational elements from each of the new research programmes to lose their primary association with their origins outside of economics, and rather be increasingly associated with 'economics'. As suggested at the outset, this may have significant implications for evolutionary and institutional themes in economics, which have been primarily associated with heterodox economics in the period of neoclassical dominance. That is, since heterodox economics has also been to some extent 'outside' economics in a manner not entirely unlike other science fields, as imports from these outside fields increasingly influence economics, it is reasonable that themes and concepts from heterodox economics will also be appropriated by the mainstream where there is overlap and shared concerns over borrowed contents. Indeed, if we characterize heterodox economics loosely as an economics with particular attachments to the kinds of investigations carried on in other science fields, the appropriation of contents from those other science fields also constitutes an appropriation of heterodox economics themes and concepts. Casual evidence for this conclusion was cited in the introduction to the paper, further attention to which, it thus seems, is certainly deserving of further research. Thus a possible convergence toward a new dominant approach in economics that assembles conceptual materials from different locations need not necessarily replicate the orthodox/heterodox divide characteristic of the period of neoclassical dominance.

\section{References}

Arrow, K. (1963 [1951]), Social Choice and Individual Values, 2nd edn, New Haven and London: Yale University Press.

Arthur, W. B. (1982), 'The Ergodic Theorems of Demography: A Simple Proof', Demography, 19(4): 439-445.

Arthur, W. B. (1994), 'Inductive Reasoning and Bounded Rationality', American Economic Review, 84(2): 406-411.

Becker, G. (1976), The Economic Approach to Human Behavior, Chicago: University of Chicago Press.

Blaug, M. (2003), 'The Formalist Revolution of the 1950s', in W. Samuels, J. Biddle, and J. Davis (eds), A Companion to the History of Economic Thought, Oxford: Blackwell, pp. 395-410.

Camerer, C. (2003), Behavioral Game Theory: Experiments in Strategic Interaction, Princeton, NJ: Princeton University Press.

Camerer, C. and G. Loewenstein (2003), 'Behavioral Economics: Past, Present, Future', in Camerer, Loewenstein, and Rabin (eds), Advances in Behavioral Economics, Princeton, NJ: Princeton University Press.

Cohen, A. and G. Harcourt (2003), 'Whatever Happened to the Cambridge Capital Theory Controversies', Journal of Economic Perspectives, 17: 199-214.

Colander, D. (2000), 'The Death of Neoclassical Economics', Journal of the History of Economic Thought, 22(2): 127-144; reprinted in Colander (2001). 
Colander, D. (2001), The Lost Art of Economics, Cheltenham: Edward Elgar.

Colander, D. (2005), 'What Economists Teach and What Economists Do', Journal of Economic Education, 36(3): 249-260.

Colander, D., R. Holt, and B. Rosser (2004), The Changing Face of Economics: Interviews with Cutting Edge Economists, Ann Arbor, MI: University of Michigan Press.

Cubitt, R., C. Starmer, and R. Sugden (2001), 'Discovered Preferences and the Experimental Evidence of Expected Utility Theory', Journal of Economic Methodology, 89(30): 385414.

David, P. (1994), 'Why are Institutions the "Carriers of History": Path Dependence and the Evolution of Conventions, Organizations and Institutions', Structural Change and Economic Dynamics, 5: 205-220.

David, P. (1985), 'Clio and the Economics of QWERTY: The Necessity of History', American Economic Review, 75: 332-337.

Davis, J. (2002), 'The History of Economics as a Subdiscipline: The Role of the History of Economics Society Meetings', in E. Weintraub (ed.), The Future of the History of Economics, Durham: Duke University Press, pp. 62-76.

Davis, J. (2003), 'Economic Methodology Since Kuhn', In W. Samuels, J. Biddle, and J. Davis (eds), The Blackwell Companion to the History of Economic Thought, Oxford: Blackwell, pp. 571-587.

Davis, J. (2006), 'Heterodox Economics: The Fragmentation of the Mainstream, and Embedded Individual Analysis', in R. Garnett and J. Harvey (eds), The Future of Heterodox Economics, Ann Arbor, MI: University of Michigan Press.

Frey, B. and M. Benz (2005), 'From Imperialism to Inspiration: A Survey of Economics and Psychology', J. Davis, A. Marciano, and J. Runde (eds), Elgar Companion to Economics and Philosophy, Cheltenham: Edward Elgar, pp. 61-83.

Grossbard-Schechtman, S. and C. Clague (eds) (2002), The Expansion of Economics: Towards an Inclusive Social Science, Armonk, NY: M.E. Sharpe.

Hands, D. (2001), Reflection without Rules: Economic Methodology and Contemporary Science Theory, Cambridge: Cambridge University Press.

Hausman, D. (1992), The Inexact and Separate Science of Economics, Cambridge: Cambridge University Press.

Kirman, A. (1989), 'The Intrinsic Limits of Modern Economic Theory: The Emperor Has No Clothes', Economic Journal, 99 (Conference 1989): 126-139.

Klaes, M. (2000), 'The History of the Concept of Transactions Costs: Neglected Aspects', Journal of the History of Economic Thought, 22(2): 191-216.

Mirowski, P. (1989), More Heat than Light: Economics as Social Physics, Physics as Nature's Economics, Cambridge: Cambridge University Press.

Mirowski, P. (2002), Machine Dreams: Economics Becomes a Cyborg Science, Cambridge: Cambridge University Press.

Mirowski, P. and E.-M. Sent (2001), Science Bought and Sold: Essays in the Economics of Science, Chicago: University of Chicago Press.

Morgan, M. and M. Rutherford (eds) (1998), From Interwar Pluralism to Postwar Neoclassicism, Durham: Duke University Press.

Rizvi, S. (1994), 'The Microfoundations Project in General Equilibrium Theory', Cambridge Journal of Economics, 18: 357-377.

Sen, A. (1970), 'The Impossibility of a Paretian Liberal', Journal of Political Economy, 78(1): $152-157$.

Sent, E.-M. (1998), 'Engineering Dynamic Economics', in J. Davis (ed.), New Economics and Its History, Durham: Duke University Press, pp. 41-62. 
Smith, V. (1989), 'Theory, Experiment and Economics', Journal of Economic Perspectives, 3(1): 151-169.

Smith, V. (1994), 'Economics in the Laboratory', Journal of Economic Perspectives, 8(1): 113-131.

Sonnenschein, H. (1985), 'Comment', in K. Arrow and S. Honkapohja (eds), Frontiers of Economics, Oxford: Blackwell.

Thaler, R. (1987), 'Anomalies: The January Effect', Journal of Economic Perspectives, 1(1): 197-201.

Weintraub, E. (ed.) (2002), The Future of the History of Economics, Durham: Duke University Press. 